\title{
High Performance Lithium-Manganese-Rich Cathode Material with
}

\section{Reduced Impurities}

Zhong Wang ${ }^{\mathrm{a}, \mathrm{b}}$, Yanping Yin ${ }^{\mathrm{a}, \mathrm{b}}$,Yang Ren ${ }^{\mathrm{c}}$, ZhenyaoWang ${ }^{\mathrm{a}, \mathrm{b}}$, Min Gao $^{\mathrm{a}, \mathrm{b}}$, Tianyuan $^{\mathrm{M}}{ }^{\mathrm{d}}$, Weidong Zhuang ${ }^{\mathrm{a}, \mathrm{b}}$, Shigang $\mathrm{Lu}^{\mathrm{a}, \mathrm{b} *}$, Ailing Fan ${ }^{\mathrm{e}}$, Khalil Amine ${ }^{\mathrm{d}}$, and Zonghai Chen ${ }^{\mathrm{d} *}$

a) General Research Institute of Nonferrous Metals, No.2 Xinjiekou Wai Street, Xicheng District, Beijing, 100088, China

b) China Automotive Battery Research Institute Co. Ltd., Beijing,101407, China

c) X-ray Science Division, Advanced Photon Sources, Argonne National

Laboratory, 9700 South Cass Avenue, Argonne, IL 60439, USA

d) Chemical Sciences and Engineering Division, Argonne National Laboratory, Argonne, IL 60439, USA

e) College of Materials Science and Engineering, Beijing University of Technology, Beijing, 100124, China

*Corresponding author:

lusg8867@163.com(S. Lu),Zonghai.Chen@anl.gov (Z.Chen).

\begin{abstract}
Lithium-manganese-rich transition metal oxides have attracted substantial R\&D attention due to their potential for high energy-density lithium-ion batteries. In this work, in situ high-energy X-ray diffraction was deployed to investigate the phase evolution during the solid-state synthesis of $\mathrm{Li}\left[\mathrm{Li}_{0.2} \mathrm{Mn}_{0.54} \mathrm{Ni}_{0.13} \mathrm{Co}_{0.13}\right] \mathrm{O}_{2}$.A step-wise consumption of the starting materials was observed during the one-step heating process primarily due to the
\end{abstract}


heterogeneous nature of the precursor. According to observations from in situ highenergy X-ray diffraction, a two-step process was adopted to minimize the elemental heterogeneity of the final product. The electrochemical characterization results showed a substantial improvement on the reversible specific capacity for the material synthesized through the two-step process.

Keyword: lithium-manganese-rich transition metal oxide; cathode; lithium-ion battery; heterogeneity; in situ; high-energy X-ray diffraction

\section{Introduction}

Lithium-rich transition metal oxides are widely considered as layered-layered integrated $(\mathrm{M}=\mathrm{Ni}, \mathrm{Co}, \mathrm{Mn})$ component [1-4]. It is widely accepted that the occupation of excess lithium in the transition metal layer leads to the formation of monoclinic $\mathrm{Li}_{2} \mathrm{MnO}_{3}$ component that is electrochemical inactive within the normal working potential window (below $4.4 \mathrm{~V}$ vs. $\mathrm{Li}^{+} / \mathrm{Li}$ ). It was found that the integration of inactive $\mathrm{Li}_{2} \mathrm{MnO}_{3}$ into the active $\mathrm{LiMO}_{2}$ matrix helps to stabilize the crystal structure of delithiated $\mathrm{LiMO}_{2}$ and hence substantially improves the capacity retention of lithium-rich transition metal oxides[5]. It was recently reported that the integrated $\mathrm{Li}_{2} \mathrm{MnO}_{3}$ component could be electrochemically activated at a higher potential, like $4.6 \mathrm{~V} \mathrm{vs.} \mathrm{Li}^{+} / \mathrm{Li}[4,6-10]$. When increasing the content of $\mathrm{Li}_{2} \mathrm{MnO}_{3}$ component (latterly referred as lithium-manganeserich (LMR) transition metal oxides), an extremely high specific reversible capacity, close to the theoretical capacity of stoichiometric $\mathrm{LiMO}_{2}$ counterpart, was achieved after the electrochemical activation, offering the highest specific energy density among existing 
cathode materials for lithium-ion batteries[11-13]. Despite their exceptional high capacity and low cost, the LMR materials suffer from three majordisadvantages of low initial coulombic efficiency, voltage fade and poor highrate capability, which bring about great difficulties for practicalapplications[14-16].Above all, the voltage fade process creates a big challenge to develop an effective battery management system (BMS) to precisely determine the state of charge (SOC) and state of health (SOH) of the battery packs using this class of materials, triggering serious debate over the suitability of adopting these materials for automobile applications. Nevertheless, this class of materials still holds great promise for applications in single-cell devices, like portable electronics.

In the open literature, lithium-manganese transition metal oxides can be synthesized through various approaches including hydrothermal routes[17-22], coprecipitation process[23-29], spraydrying approach[30-35] and solid-state reaction[3639]. Hydrothermal route is widely used to synthesize nanomaterials at a relatively low temperature with reduced synthesis time[1,3,20,35], generally resulting in materials with substantially higher rate capabilities, but with low loading density and low volumetric energy density. On the other hand, the co-precipitation approach has been widely adopted for industrial application primarily due to its high scalability, ease of control on the particle size and the particle morphology[23], and unique capability to control the elemental distribution of transition metal elements at the particle level[40-43], However, it is difficult for co-precipitation methods to control precisely the composition of the precursor powders because the precipitation conditions of metal ions are strongly affected by the types of metal components[44].Comparing to co-precipitation process, solid-state synthesis is expected to have a reduced cost, and reduced synthesis time. However, the 
major disadvantage of the solid-state synthesis is the difficulty in controlling the segregation of transition metal elements in the primary particle level[39], which in turn has significant impact on the electrochemical performance of the final cathode materials. In this work, we report our latest effort in developing a low-cost and scalable synthesis route for lithium-manganese-rich transition metal oxides using a combination of ball milling, spray drying and a solid-state synthesis. In situ high-energy X-ray diffraction was deployed to investigate the phase evolution during the synthesis of lithiummanganese-rich transition metal oxides, and to guide the material synthesis to reduce the segregation of transition metal elements.

\section{Experimental}

\section{Synthesis of lithium-manganese-rich transition metal oxides}

\section{1) The Synthesis of sample S1a and S1b}

$\mathrm{Li}_{2} \mathrm{CO}_{3}, \mathrm{MnCO}_{3}, \mathrm{Co}_{3} \mathrm{O}_{4}$ and $\mathrm{NiO}$ with anatomic molar ratio of 1.2:0.54:0.13:0.13were used as the starting materials. The mixture powders were ball milled to ground with zirconium dioxide at room temperature with deionized water as dispersant. Then, the suspension of mixture was dried by a spray drying instrument. The precursors were heated to $750^{\circ} \mathrm{C}$ or $900{ }^{\circ} \mathrm{C}$ for $10 \mathrm{~h}$ and cooled down to room temperature in the furnace, to obtain the final lithium-manganese-rich transition metal oxides sample S1a or S1b respectively.

\section{2) The Synthesis of sample S2a and S2b}

A mixture containing $\mathrm{Li}_{2} \mathrm{CO}_{3}, \mathrm{MnCO}_{3}, \mathrm{Co}_{3} \mathrm{O}_{4}$ and $\mathrm{NiO}$ with an atomic molar ratio of 1.2:0.54:0.13:0.13 was carefully mixed. The mixture powders werepreheated at 600 
${ }^{\circ} \mathrm{C}$,then the preheated powders were ball milled to ground with zirconium dioxide at room temperaturewith deionized water as dispersant. Then, the suspension of mixture was dried by a spray drying instrument. The precursors were heated to $750^{\circ} \mathrm{C}$ or $900{ }^{\circ} \mathrm{C}$ for $10 \mathrm{~h}$ and cooled down to room temperature in the furnace, to obtain the final lithiummanganese-rich transition metal oxides sample S2a or S2b respectively.

\section{Physical characterization of materials}

\section{1) Ex situ high-energy X-ray diffraction (HEXRD)}

The HEXRD patterns of synthesized Samples at various conditions were collected at sector 11-ID-C of the Advanced Photon Source (APS) at Argonne National Laboratory. The wavelength of the X-ray beam used was $0.11798 \AA$.

\section{2) In situ HEXRD}

The structural evolution of materials during the solid-state synthesis of $\mathrm{Li}\left[\mathrm{Li}_{0.2} \mathrm{Mn}_{0.54} \mathrm{Ni}_{0.13} \mathrm{Co}_{0.13}\right] \mathrm{O}_{2}$ was studied using in situ high-energy X-ray diffraction. Precursors of $\mathrm{Li}\left[\mathrm{Li}_{0.2} \mathrm{Mn}_{0.54} \mathrm{Ni}_{0.13} \mathrm{Co}_{0.13}\right] \mathrm{O}_{2}$ were prepared as described above. The precursor was pressed into a $2 \mathrm{~mm}$ thick pellet with $5 \mathrm{~mm}$ diameter. The pellet was then placed in a programmable furnace (Linkam TS 1500) vertically with the X-ray beam aiming at the center of the pellet. The sample was then heated from room temperature to $1000^{\circ} \mathrm{C}$ with a constant heating rate of $2{ }^{\circ} \mathrm{C} \mathrm{min}^{-1}$. The in situ HEXRD experiment was carried out at sector 11-ID-C of the APS. The wavelength of the X-ray beam was prefixed at $0.11798 \AA$. The high energy X-ray source was selected for its excellent penetration capability to detect structural changes on bulk part of the sample. During the in situ solid-state synthesis, a 2D X-ray detector was deployed to collect one XRD pattern 
every 20 s. Rietveld refinement of interested patterns was then carried out using General Structure Analysis Software (GSAS).

\section{3) Other Physical characterization}

The particles morphology and size of the powders were determined using scanning electron microscopy (SEM, Hitachi S4700).

Specific surface area measurements were performed on ST-2000 according to the standard GB/T 13390-2008.

The particle-size distribution of the powders (secondary particles) was measured with Malvern MS3000.

\section{Covariance analysis of in situ HEXRD}

The covariance analysis (see Eq. (1)) was applied to calculate the mathematical similarity between two different XRD patterns ( $\mathrm{r} 1$ and $\mathrm{r} 2$ ). Both of which are a series of X-ray intensity at different $2 \theta$ values. When two spectra are identical to each other, the covariance value of Eq. (1) equals to 1; a smaller number will be given when two spectra have some difference.

$$
\operatorname{CORR}(\mathrm{r} 1, \mathrm{r} 2)=\frac{\sum_{i} r 1(i) * r 2(i)}{\sqrt{\sum_{i} r 1(i) * r 1(i) * \sqrt{\sum_{i} r 2(i) * r 2(i)}}}
$$

\section{Electrochemical Characterization}

Electrochemical characterization on synthesized samples $\mathrm{Li}\left[\mathrm{Li}_{0.2} \mathrm{Mn}_{0.54} \mathrm{Ni}_{0.13} \mathrm{Co}_{0.13}\right] \mathrm{O}_{2}$ were performed by fabricating 2032 coin cells. For making electrode, 80 wt. \% of the cathode material was blended with 10 wt. \% of Super-P, and 10 wt. \% of polyvinylidene difluoride (PVDF) dissolved in N-methyl l-2-pyrrolidene (NMP) 
and coated onto $\mathrm{Al}$ foil. After drying the electrode overnight at $80{ }^{\circ} \mathrm{C}$ in vacuum, the coin cells were assembled in an argon filled glove box (MBraun). $1 \mathrm{M} \mathrm{LiPF} 6$ in a 1:1:1 ethylene carbonate (EC) / dimethyl carbonate (DMC) / methyl ethyl carbonate (EMC) was used as electrolyte, lithium foil as anode and Celgard 2400 membrane as separator. The cells were allowed to rest for $10 \mathrm{~h}$ and charge-discharged on a battery tester (LAND CT-2001A, China) between 2.0 and $4.8 \mathrm{~V}$ (If not specified, vs. $\mathrm{Li}^{-\mathrm{Li}^{+}}$) at room temperature.

\section{Results and discussion}

In order to illustrate the potential impact of the synthesis condition on the structure of the final product (LMR material), in situ high-energy X-ray diffraction was carried during the thermal treatment of the precursor materials prepared in different approaches. Figure 1a shows the contour plot of the HEXRD patterns collected during the thermal treatment of the precursor prepared using the one-step process. In Figure 1a, the color of each pixel depicts the measured X-ray intensity at the specific diffraction angle (20) and the specific temperature; a red color means a high X-ray intensity and a blue one means a low X-ray intensity. At the beginning of the experiment, the XRD patterns can be fully indexed with the starting materials composing of $\mathrm{Co}_{3} \mathrm{O}_{4}$ (PDF\#74-2120), $\mathrm{MnCO}_{3}$ ( $\mathrm{PDF}$ \#44-1472), NiO (PDF \#44-1159), and $\mathrm{Li}_{2} \mathrm{CO}_{3}$ (PDF\#22-1141) (see Figure 1b). During the initial heating process, all diffraction peaks shifted left with the heating temperature; this is primarily due to the thermal expansion of crystal lattice. One can easily see the disappearance of the diffraction peaks from the raw materials and emergence of a set of

new peaks for the layered structure within the temperature window between $300{ }^{\circ} \mathrm{C}$ and 
$450{ }^{\circ} \mathrm{C}$, which is a good indication of ongoing solid-state reaction from the raw materials to the layered cathode material. It can also be seen that the fingerprint peaks of $\mathrm{Li}_{2} \mathrm{MnO}_{3}$ component at about $1.5-1.6^{\circ}$, appeared when the temperature is above about $700{ }^{\circ} \mathrm{C}$. To catch more subtle structural changes during the thermal treatment, a covariance analysis was carried out to calculate the similarity between two HEXRD patterns collected at different time/temperature; the contour plot of the results from covariance analysis is shown in Figure 1c, and the change of the covariance value between adjunct HEXRD patterns is shown in Figure 1d. Both Figure 1c and Figure 1d clearly show three major changes occurred during the heating process, one reaction occurred at about $290{ }^{\circ} \mathrm{C}$, and the other two occurred at about $450{ }^{\circ} \mathrm{C}$ and $890{ }^{\circ} \mathrm{C}$, respectively.

Figure 2 shows the areal plot of in situ HEXRD data for a better illustration of changes on the XRD pattern with the heating process. Figure 2a shows the intensity of the raw materials started to decrease when the temperature was above $200{ }^{\circ} \mathrm{C}$. However, a synchronized disappearance of the raw materials was not observed. For instance, the diffraction peak at $1.84^{\circ}$, assigned as (012) peak (d=3.6719 $\AA$ ) of $\mathrm{MnCO}_{3}$, showed a dramatic decrease at about $315{ }^{\circ} \mathrm{C}$, and completely vanished at about $510{ }^{\circ} \mathrm{C}$. Following the disappearance of $\mathrm{MnCO}_{3}$, the diffraction peaks for $\mathrm{Co}_{3} \mathrm{O}_{4}$ vanished at about $480{ }^{\circ} \mathrm{C}$, and the diffraction peaks for $\mathrm{Li}_{2} \mathrm{CO}_{3}$ remained visible up to $540{ }^{\circ} \mathrm{C}$.According toliterature reports, the reactions occurred below $600{ }^{\circ} \mathrm{C}$ may be attributed to (1) the thermal decomposition of $\mathrm{MnCO}_{3}$ in air to form $\mathrm{MnO}_{2}$ and the reaction between $\mathrm{MnO}_{2}$ and $\mathrm{Li}_{2} \mathrm{CO}_{3}$ that leads to the nucleation of $\mathrm{Li}_{2} \mathrm{MnO}_{3}$ domains[45];(2) the reaction between $\mathrm{Co}_{3} \mathrm{O}_{4}$ and $\mathrm{Li}_{2} \mathrm{CO}_{3}$ that generates $\mathrm{LiCoO}_{2} / \mathrm{Li}_{2} \mathrm{Co}_{2} \mathrm{O}_{4}[46]$. It is also believed that the 
integrated layered-layered composite structure $\left(\mathrm{Li}_{2} \mathrm{MnO}_{3} \cdot \mathrm{LiMO}_{2}\right)$ was not formed at such a low temperature since the peak intensity for NiO didn’t show any significant decrease when the temperature was below $600{ }^{\circ} \mathrm{C}$. Figure $2 \mathrm{~b}$ clearly shows that a major decrease on intensity of $\mathrm{NiO}$ peaks occurred at about $800{ }^{\circ} \mathrm{C}$. However, existence of $\mathrm{NiO}$ in the material can be clearly seen even when the temperature was as high as $1000{ }^{\circ} \mathrm{C}$. The step-wise reactions among the raw materials can be reasonably attributed to the heterogeneous nature of the precursor prepared using spray drying process; the secondary particles are composed of loosely packed nanoparticles of various raw materials, and a homogeneous mixing between transition metal elements at the primary particle level was not achieved.

The step-wise reaction mode can be further supported by the evolution of an intermediate phase as shown in Figure 3. The intermediate phase started to appear at about $410{ }^{\circ} \mathrm{C}$ and disappeared at about $910{ }^{\circ} \mathrm{C}$. This intermediate showed characteristic peaks at $1.44^{\circ}, 2.78^{\circ}, 3.35^{\circ}, 3.65^{\circ}, 4.35^{\circ}, 4.74^{\circ}$, and $4.96^{\circ}$ (see Figure 3). Accordingly to the $2 \theta v a l u e s$ of these peaks, the intermediate can be assigned to a manganese-rich phase like $\mathrm{MnO}_{2}$ (PDF \# 44-0992) or $\mathrm{Li}_{2} \mathrm{Mn}_{2} \mathrm{O}_{4}$ (PDF \# 84-1524) or a cobalt-based phase like $\mathrm{LiCoO}_{2}$ (PDF \# 70-2685) and $\mathrm{Li}_{2} \mathrm{Co}_{2} \mathrm{O}_{4}$ (PDF \# 70-2685). Rietveld refinement was carried out to fit the HEXRD patterns collected at temperatures $600^{\circ} \mathrm{C}$ using the $\mathrm{Li}_{1.2}\left(\mathrm{Ni}_{0.13} \mathrm{Co}_{0.13} \mathrm{Mn}_{0.54}\right) \mathrm{O}_{2}(\mathrm{R}-3 \mathrm{~m}), \mathrm{NiO}$ (Fm-3m)and $\mathrm{Li}_{2} \mathrm{Mn}_{2} \mathrm{O}_{4}$ (I41/amd). A good fit for the sample was obtained (Fig. S1), showing the intermediate is $\mathrm{Li}_{2} \mathrm{Mn}_{2} \mathrm{O}_{4}$. Considering the $\mathrm{Co}_{3} \mathrm{O}_{4}$ has disappeared completely in $480{ }^{\circ} \mathrm{C}$, the intermediate should also contain element Co, soit should be mainlyLi ${ }_{2}\left(\mathrm{Mn}_{\mathrm{x}} \mathrm{Co}_{1-\mathrm{x}}\right)_{2} \mathrm{O}_{4}$. 
The step-wise solid-state reactions discussed above are mostly resulted from the heterogeneous mixing among different ingredients. Unlike the co-precipitation reaction, the secondary particles prepared are physical agglomeration of individual nanoparticles of $\mathrm{MnCO}_{3}, \mathrm{Co}_{3} \mathrm{O}_{4}, \mathrm{NiO}$ and $\mathrm{Li}_{2} \mathrm{CO}_{3}$, and a homogeneous mixing was not achieved. Hence, the formation of the layered-structures and intermixing between transition metal elements was controlled by the mobility of transition metal ions in the oxygen framework, leading to the step-wise disappearance of the raw materials during the solidstate synthesis. One can reasonably speculate that nickel ions, eitherNi ${ }^{2+}$ or $\mathrm{Ni}^{3+}$, have lower mobility in the oxygen framework than their manganese and cobalt-based counterparts[47]. Therefore, a small amount of $\mathrm{NiO}$ was still visible even when the sample was heated up to $1000^{\circ} \mathrm{C}$. In practice, there are two possible approaches to mitigate the intermixing barrier. One is to sinter the materials at an elevated temperature for a higher mobility of transition metal ions and/or with extended period of sintering time. This approach is effective to improve the degree of utilization ofNiO raw material, but the migration of highly mobile $\mathrm{Mn} / \mathrm{Co}$ ions can lead to the substantial growth of the primary particles. The alternative approach, which was adopted for this work, is pretreating the mixture of the raw materials for a partially completed reaction, followed by a ball-milling, to regenerate the fresh Ni-Co and Ni-Mn interface to shorten the diffusion length for nickel ions during the final sintering step.

Figure 4a shows the contour plot of the in situ HEXRD profiles during the heating of a preheated precursor sample. The pre-heated sample appeared like a layered material right at the beginning of the in situ experiment, with several minor peaks contributed from the residual $\mathrm{NiO}$ from the pre-heating step. The existence of $\mathrm{NiO}$ in the pre-heated 
sample is clearly supported by extra peaks showing at $3.23^{\circ}, 4.55^{\circ}$, and $5.32^{\circ}$, respectively (see Figure $4 \mathrm{~b}-\mathrm{d}$ for a better illustration). Figure $4 \mathrm{~b}-\mathrm{d}$ shows that the intensity of diffraction peaks from $\mathrm{NiO}$ started to decrease when the temperature was higher than $600^{\circ} \mathrm{C}$, and that those peakscompletely disappeared at $815^{\circ} \mathrm{C}$. This clearly demonstrated that the pre-heating andball-milling process significantly improves the migration efficiency of nickel ions during the sintering process, will achievebetter intermixing between transition metal elements, and making it possible to sinter the material at a reduced temperature to minimize the growth of the primary particles during the sintering process.Uniform elemental distribution is very important.Significant nonuniform $\mathrm{Ni}$ distribution of LMR cathodesat atomic level willweaken nickelmanganese interactions, leading to easyreduction of the manganese ions and fast voltage/capacityfade.The samples with uniform atomic level spatial distribution demonstrate much bettercapacity retention and much smaller voltage fade as compared to those with significant nonuniform Ni distribution[12,15].

Figure 5 shows the evolution of the crystal structure as well as the disappearance of impurities (NiO and a spinel phase) during the solid-state synthesis for both preparation routes. In order to simplify the refinement, the diffraction data within the fingerprint area for $\mathrm{Li}_{2} \mathrm{MnO}_{3}$ (from $1.5^{\circ}$ and $2.2^{\circ}$ ) were excluded from refinement. Figures 5a-c show that cell parameters ( $a, b, c$, and volume) for both samples increased steadily with the heating temperature. Particularly, the cell parameters for the material prepared with two-step approach showed higher values than those for the material synthesized by one-step approach. This implies that the two-step process can lead to a higher degree of completeness of converting the precursor material into the desired lithium transition 
metal oxides than the one-step process. This implication can be further validated with the disappearance of the impurities ( $\mathrm{NiO}$ and spinel phase) as shown in Figure 5d and 5e. Both Figures 5d and 5e shows that the content of the both impurities decreased steadily with the process of solid-state synthesis. It is shown that the no detectable amount of impurities was observed for the two-step process at a temperature higher than $850^{\circ} \mathrm{C}$. However, a small amount of $\mathrm{NiO}$ and spinel phase still existed in one-step process even when the temperature is as high as $1000^{\circ} \mathrm{C}$. These results indicated that the two-step process can enable us to achieve a maximal completeness of solid-state reaction at a relatively low temperature and in a shorter period of time with a minimal amount of impurities for a better electrochemical performance.

To validate the finding of the in situ experiment, four samples were prepared using two approaches without (for sampleS1a and S1b) and with (for sample S2a and S2b) preheating. Figure 6 shows the scanning electron microscopy (SEM) images of the precursors(see Figure 6a-d) and final powders (see Figure 6e-l)prepared using two different processes. It is demonstrated in Figure 6 that spherical powders, composing of nanometer-sized primary particles, and the spherical morphology was maintained after the sintering process. Particle size analysisofprecursorsshows that the size of secondary particles for sample S2a\&b is slightly smaller than that for sample S1a\&b.Table 1 summarizes the results from the basic particle characterization. Average particle sizeof the samples was determined by measuring the dimension of theparticles from the enlarged SEM images. Samples S1a and S2a synthesized at a low temperaturehave smaller primary particles size: the particlessizes are below 100nm. Increasing temperature leads to larger particles. Sample S2b has smaller particles size than sample 
S1b, although they were synthesized at the same temperature, indicating that the size of primary particles was contributed from not only the sintering temperature but also the preparation process. The pre-heatingandball-milling processes arebenefitting to controlling the coarsening of particles during the sintering process. The smaller particle sizes are to the benefit of shortening the diffusion pathway of lithium ions[15,48].

High-energy X-ray diffraction characterization on all samples shows that all samples have $\mathrm{LiMO}_{2}(\mathrm{R}-3 \mathrm{~m})$ component; but substantial difference on the crystallinity of the $\mathrm{Li}_{2} \mathrm{MnO}_{3}(\mathrm{C} 2 / \mathrm{m})$ component was observed (see Figure 7). Sample S1b and S2b were prepared at a higher temperature, and a set of well-defined superlattice diffraction peaksfor $\mathrm{Li}_{2} \mathrm{MnO}_{3}$ component between $1.5-2.2^{\circ}$ was observed and was successfully indexed as shown in Figure 7. However, samplesS1a and S2a only showed a poorly resolved broad peak at about $1.6^{\circ}$, indicating that the $\mathrm{Li}_{2} \mathrm{MnO}_{3}$ component in these samples has a small domain size with a lack of long term ordering, an increase in the amount of stacking faults.From thermodynamics,a material withdefects has the higher energy state, which may lower the activationbarrier for $\mathrm{Li}^{+}$diffusion and allow $\mathrm{Li}^{+}$to be extracted at a lowerpotential[49].For sample S1a, a weak peak around the two theta of $3.1^{\circ}$ are assigned to $\mathrm{NiO}$, show the solid-state reaction is not completed yet. The rietveld refinement of ex situ HEXRD data revealved that the samples prepared with one-step process contained a small amount ( $1 \%)$ ofNiOregardless of the sintering temperature. On the other hand, the samplesprepared with the pre-heating step showed no sign of detectable amount of $\mathrm{NiO}$; this can be very beneficial for the electrochemical performance of the cathode material. 
Figure 8a shows voltage profiles during the first charge/discharge cycling of halfcells using cathode materials S1a, S1b, S2a and S2b. The current density was 0.1C, assuming that the $1 \mathrm{C}$ rate is equivalent to $200 \mathrm{~mA} \mathrm{~g}^{-1}$. During the initial charge up to 4.5 $\mathrm{V}$ vs. $\mathrm{Li}^{+} / \mathrm{Li}$, both samples delivered roughly the same capacity, but the cell containing S1b showed a slightly larger polarization, which might be contributed from the large primary particle size in sample S1b. When the potential was higher than $4.5 \mathrm{~V} \mathrm{vs.} \mathrm{Li}^{+} / \mathrm{Li}$, the cell containing S2ahas the highest initial discharge capacity and coulombic efficiency, whilethe S1b is the lowest one in both theinitial discharge capacityand the coulombic efficiency. The initial discharge capacity of the cell containing S2a was about $40 \mathrm{mAhg}^{-1}$ higher than that of the cell using S1b, while coulombic efficiencyof the cell containing S2awas about 8\%higher. Sample S1a,S2a and S2b have higher coulombic efficiencies than S1b,which may be attributed to thesmaller particle size.The LMR materials suffer from low initial coulombic efficiency usually.The large initial irreversible capacity loss is consideredusuallyattributed to an irreversible removal of partial lithium as $\mathrm{Li}_{2} \mathrm{O}$ along with an elimination of the oxygen vacancies from thecrystal lattice produced during the first charge[14,50].

Figures $8 \mathrm{~b}$ and $8 \mathrm{c}$ compare the voltage profiles of Li/S2a cells that were cycled to different upper cutoff potential (from $4.2 \mathrm{~V}$ to $4.8 \mathrm{~V}$ ). It can be seen that the reversible capacity of the material S2a consistently increased with the upper cutoff potential; a substantial jump on the reversible capacity was obtained when the upper cutoff potential was higher than $4.4 \mathrm{~V}$. When the upper cutoff potential was set to $4.8 \mathrm{~V} \mathrm{vs.} \mathrm{Li}^{+} / \mathrm{Li}$, the cell delivered a reversible capacity of about $290 \mathrm{mAhg}^{-1}$. 
The rate and cycling performances of the samples with different preparation process were characterized at room temperature as shown in Figure 9. Figure 9a shows the rate capabilityof samples. Different rates were tested in a sequential manner $(0.1 \mathrm{C}, 0.2 \mathrm{C}$, $0.5 \mathrm{C}, 1 \mathrm{C}$ and $3 \mathrm{C}$ ) for three cycles at each step between $2-4.8 \mathrm{~V}$ at room temperature. The material S2a and bshow better rate capabilitythan S1a and b.The better rate capability of samples S2a and b is probably due to the smaller primary particles[51]and the absence of the impurity (NiO).Figure 9b shows the discharge capacity of samples during the long term cycling The cell was initially charged and discharged within the voltage window of 2-4.8 $\mathrm{V}$ for activation (1-3 cycles), and then operated between 2 and $2.6 \mathrm{~V}$ for the subsequent cyclesunder $1 \mathrm{C}$ rate $\left(1 \mathrm{C}=200 \mathrm{~mA} \mathrm{~g}^{-1}\right)$. It is clear that the cell using S2a had the highest discharge capacity in those samples, whilethe cell using S2b had the best cycle performance.The results shown in Figure 9 imply that samples sintered at higher temperature have better cycle performance.The sample S2athough sintered at lower temperature has a much higher discharge capacity and similar cycle performancecompare with those of the sample S1b.It is mostly contributed by the higher degree of electrochemical activation during the initial charge/discharge cycling, resulting in more useable sites to store lithium in the activated cathode material, and the absence of $\mathrm{NiO}$ impurity that impede the charge/discharge of the cathode material.

\section{Conclusion}

In situ high-energy X-ray diffraction was utilized to investigate the structure evolution during the solid-state synthesis of lithium-manganese-rich transition metal oxides. The results of the in situ experiment indicated a step-wise reaction among the raw materials. 
It was demonstrated that an extra ball-milling process after the pre-heating effectively reduce the length of diffusion path for transition metal element during the sintering process, and hence a better intermixing between transition metal elements was achieved at a reduced temperature. As a result,phase pure material can be obtained, anda better electrochemical performance was obtained.

\section{Acknowledgement}

Research was funded by the National Nature Science Foundation of China (No. 51302017), and the Science and Technology Commission of Beijing (No. Z121100006712002), U.S. Department of Energy (DOE), Vehicle Technologies Office. Support from Tien Duong and Peter Faguy of the U.S. DOE's Office of Vehicle Technologies Program, are gratefully acknowledged. Argonne National Laboratory is operated for the US Department of Energy by U Chicago Argonne, LLC, under contract DE-AC02-06CH11357. Use of the Advanced Photon Source (APS) that was supported by the U. S. Department of Energy, Office of Science, Office of Basic Energy Sciences, under Contract No. DE-AC02-06CH11357.

\section{References}

[1] D.L. Ye, L.Z. Wang, Mater. Technol. 29 (2014) A59-A69.

[2] W. Liu, G. Fang, B. Xia, H. Sun, S. Kaneko, D. Li, RSC Adv. (2013) 15630 15635.

[3] B. Ammundsen, J. Paulsen, Adv. Mater. 13 (2001) 943-956.

[4] N.S. Choi, Z. Chen, S. a. Freunberger, X. Ji, Y.K. Sun, K. Amine, G. Yushin, L.F. Nazar, J. Cho, P.G. Bruce, Angew. Chemie - Int. Ed. 51 (2012) 9994-10024.

[5] J. Zheng, S. Deng, Z. Shi, H. Xu, H. Xu, Y. Deng, Z. Zhang, G. Chen, J. Power Sources 221 (2013) 108-113. 
[6] Z. Lu, D.D. MacNeil, J.R. Dahn, Electrochem. Solid-State Lett. 4 (2001) A191A194.

[7] M. Lengyel, X. Zhang, G. Atlas, H.L. Bretscher, I. Belharouak, R.L. Axelbaum, J. Electrochem. Soc. 161 (2014) A1338-A1349.

[8] P.K. Nayak, J. Grinblat, M. Levi, B. Markovsky, D. Aurbach, J. Electrochem. Soc. 161 (2014) A1534-A1547.

[9] M.M. Thackeray, C. Wolverton, E.D. Isaacs, Energy Environ. Sci. 5 (2012) 78547863.

[10] J.R. Croy, K.G. Gallagher, M. Balasubramanian, Z. Chen, Y. Ren, D. Kim, S.-H. Kang, D.W. Dees, M.M. Thackeray, J. Phys. Chem. C 117 (2013) 6525-6536.

[11] L. Li, K.S. Lee, L. Lu, Funct. Mater. Lett. 07 (2014) 1430002.

[12] J. Zheng, M. Gu, A. Genc, J. Xiao, P. Xu, X. Chen, Z. Zhu, W. Zhao, L. Pullan, C. Wang, J.G. Zhang, Nano Lett. 14 (2014) 2628-2635.

[13] and S.P. Adrien Boulineau, Loïc Simonin, Jean-François Colin, Carole Bourbon, Nano Lett. 13 (2013) 3857-3863.

[14] W. He, J. Qian, Y. Cao, X. Ai, H. Yan, RSC Adv. 2 (2012) 3423-3429.

[15] Y. Li, Y. Bai, C. Wu, J. Qian, G. Chen, L. Liu, H. Wang, X. Zhou, F. Wu, J. Mater. Chem. A 4 (2016) 5942-5951.

[16] J.R. Croy, K.G. Gallagher, M. Balasubramanian, B.R. Long, M.M. Thackeray, J. Electrochem. Soc. 161 (2014) A318-A325.

[17] T.N.L. Doan, K. Yoo, T.K.A. Hoang, P. Chen, Front. Energy Res. 2 (2014) 1-7.

[18] J. Zheng, M. Gu, A. Genc, J. Xiao, P. Xu, X. Chen, Z. Zhu, W. Zhao, L. Pullan, C. Wang, J.G. Zhang, Nano Lett. 14 (2014) 2628-2635.

[19] N.S. Choi, Z. Chen, S. a. Freunberger, X. Ji, Y.K. Sun, K. Amine, G. Yushin, L.F. Nazar, J. Cho, P.G. Bruce, Angew. Chemie - Int. Ed. 111 (2007) 3192-3196.

[20] D. Ahn, Y. Koo, M.G. Kim, N. Shin, J. Park, J. Eom, J. Cho, T.J. Shin, J. Phys. Chem. (2010) 3675-3680.

[21] M. Tabuchi, Y. Nabeshima, M. Shikano, K. Ado, H. Kageyama, K. Tatsumi, J. Electrochem. Soc. 154 (2007) A638-A648.

[22] X. Miao, Y. Yan, C. Wang, L. Cui, J. Fang, G. Yang, J. Power Sources 247 (2014) 219-227.

[23] S.H. Park, S.H. Kang, I. Belharouak, Y.K. Sun, K. Amine, J. Power Sources 177 (2008) 177-183.

[24] Z. Chen, Y.-K. Sun, K. Amine, J. Electrochem. Soc. 153 (2006) A1818-A1822.

[25] D. Wang, I. Belharouak, G. Zhou, K. Amine, J. Electrochem. Soc. 160 (2013) A3108-A3112.

[26] B. Xu, C.R. Fell, M. Chi, Y.S. Meng, Energy Environ. Sci. 4 (2011) 2223-2233.

[27] a. R. Armstrong, M. Holzapfel, P. Novák, C.S. Johnson, S.H. Kang, M.M. Thackeray, P.G. Bruce, J. Am. Chem. Soc. 128 (2006) 8694-8698.

[28] C.S. Johnson, N. Li, C. Lefief, M.M. Thackeray, Electrochem. Commun. 9 (2007) 787-795.

[29] J.H. Lim, H. Bang, K.S. Lee, K. Amine, Y.K. Sun, J. Power Sources 189 (2009) 571-575.

[30] J. Kim, N. Kumagai, H. Chung, Electrochem. Solid-State Lett. 9 (2006) A494A498. 
[31] L. Zhang, T. Muta, H. Noguchi, X. Wang, M. Zhou, M. Yoshio, J. Power Sources 117 (2003) 137-142.

[32] M. Road, L. Chemistry, Electrochemistry 82 (2014) 438-443.

[33] M. Lengyel, G. Atlas, D. Elhassid, P.Y. Luo, X. Zhang, I. Belharouak, R.L. Axelbaum, J. Power Sources 262 (2014) 286-296.

[34] M.Y. Son, Y.J. Hong, S.H. Choi, Y.C. Kang, Electrochim. Acta 103 (2013) 110118.

[35] Z. He, Z. Wang, L. Cheng, Z. Zhu, T. Li, X. Li, H. Guo, Adv. Powder Technol. 25 (2014) 647-653.

[36] C.H. Song, a. M. Stephan, S.K. Jeong, A.R. Kim, K.S. Nahm, Y.S. Lee, J.K. Kim, H.T. Chung, Mater. Res. Bull. 41 (2006) 1487-1495.

[37] J. Wang, B. Qiu, H. Cao, Y. Xia, Z. Liu, J. Power Sources 218 (2012) 128-133.

[38] J.-K. Noh, S. Kim, H. Kim, W. Choi, W. Chang, D. Byun, B.-W. Cho, K.Y. Chung, Sci. Rep. 4 (2014) 4847.

[39] L. Croguennec, J. Bains, M. Ménétrier, A. Flambard, E. Bekaert, C. Jordy, P. Biensan, C. Delmas, J. Electrochem. Soc. 156 (2009) A349-A355.

[40] G.M. Koenig, I. Belharouak, H. Deng, Y. Sun, K. Amine, (2011) 1954-1963.

[41] Y.-K. Sun, Z. Chen, H.-J. Noh, D.-J. Lee, H.-G. Jung, Y. Ren, S. Wang, C.S. Yoon, S.-T. Myung, K. Amine, Nat. Mater. 11 (2012) 942-947.

[42] Y.-K. Sun, S.-T. Myung, B.-C. Park, J. Prakash, I. Belharouak, K. Amine, Nat. Mater. 8 (2009) 320-324.

[43] Y.-K. Sun, S.-T. Myung, M.-H. Kim, J. Prakash, K. Amine, J. Am. Chem. Soc. 127 (2005) 13411-13418.

[44] M.Y. Son, J.-K. Lee, Y.C. Kang, Sci. Rep. 4 (2014) 5752.

[45] Y. Kan, Y. Hu, J. Croy, Y. Ren, C.J. Sun, S.M. Heald, J. Bareño, I. Bloom, Z. Chen, J. Power Sources 266 (2014) 341-346.

[46] Y. Kan, Y. Hu, Y. Ren, J. Bareño, I. Bloom, Y.-K. Sun, K. Amine, Z. Chen, J. Power Sources 271 (2014) 97-103.

[47] G.-L. Xu, Y. Qin, Y. Ren, L. Cai, K. An, K. Amine, Z. Chen, J. Mater. Chem. A 3 (2015) 13031-13038.

[48] J. Liu, L. Chen, M. Hou, F. Wang, Y. Xia, J. Mater. Chem. 22 (2012) 2538025387.

[49] D.Y.W. Yu, K. Yanagida, Y. Kato, H. Nakamura, J. Electrochem. Soc. 156 (2009) A417-A424.

[50] B. Song, Z. Liu, M.O. Lai, L. Lu, Phys. Chem. Chem. Phys. 14 (2012) 1287512883.

[51] J.-H. Park, J. Lim, J. Yoon, K.-S. Park, J. Gim, J. Song, H. Park, D. Im, M. Park, D. Ahn, Y. Paik, J. Kim, Dalton Trans. 41 (2012) 3053-3059. 


\section{Captions}

\section{Tables}

Table 1.The results from the basic particle characterization

\begin{tabular}{|c|c|c|c|c|}
\hline $\begin{array}{c}\text { The } \\
\text { name of } \\
\text { sample }\end{array}$ & $\begin{array}{c}\text { Secondary } \\
\text { particles size } \\
\mathbf{( D 5 0 , \mu \mathbf { m } )}\end{array}$ & $\begin{array}{c}\text { Specific } \\
\text { surface area } \\
\mathbf{( m}^{\mathbf{2}} \mathbf{g}^{-\mathbf{1}} \mathbf{)}\end{array}$ & $\begin{array}{c}\text { Average primary } \\
\text { particle size } \\
\mathbf{( n m})\end{array}$ & $\begin{array}{c}\text { Tap density } \\
\mathbf{( m}^{\mathbf{3}} \mathbf{g}^{\mathbf{- 1}} \mathbf{)}\end{array}$ \\
\hline S1a & 5.3 & 6.31 & $\sim 89$ & 0.7 \\
\hline S1b & 5.3 & 1.47 & $\sim 280$ & 0.8 \\
\hline S2a & 4.5 & 6.44 & $\sim 92$ & 1.1 \\
\hline S2b & 4.5 & 2.28 & $\sim 140$ & 1.2 \\
\hline
\end{tabular}

\section{Figures}
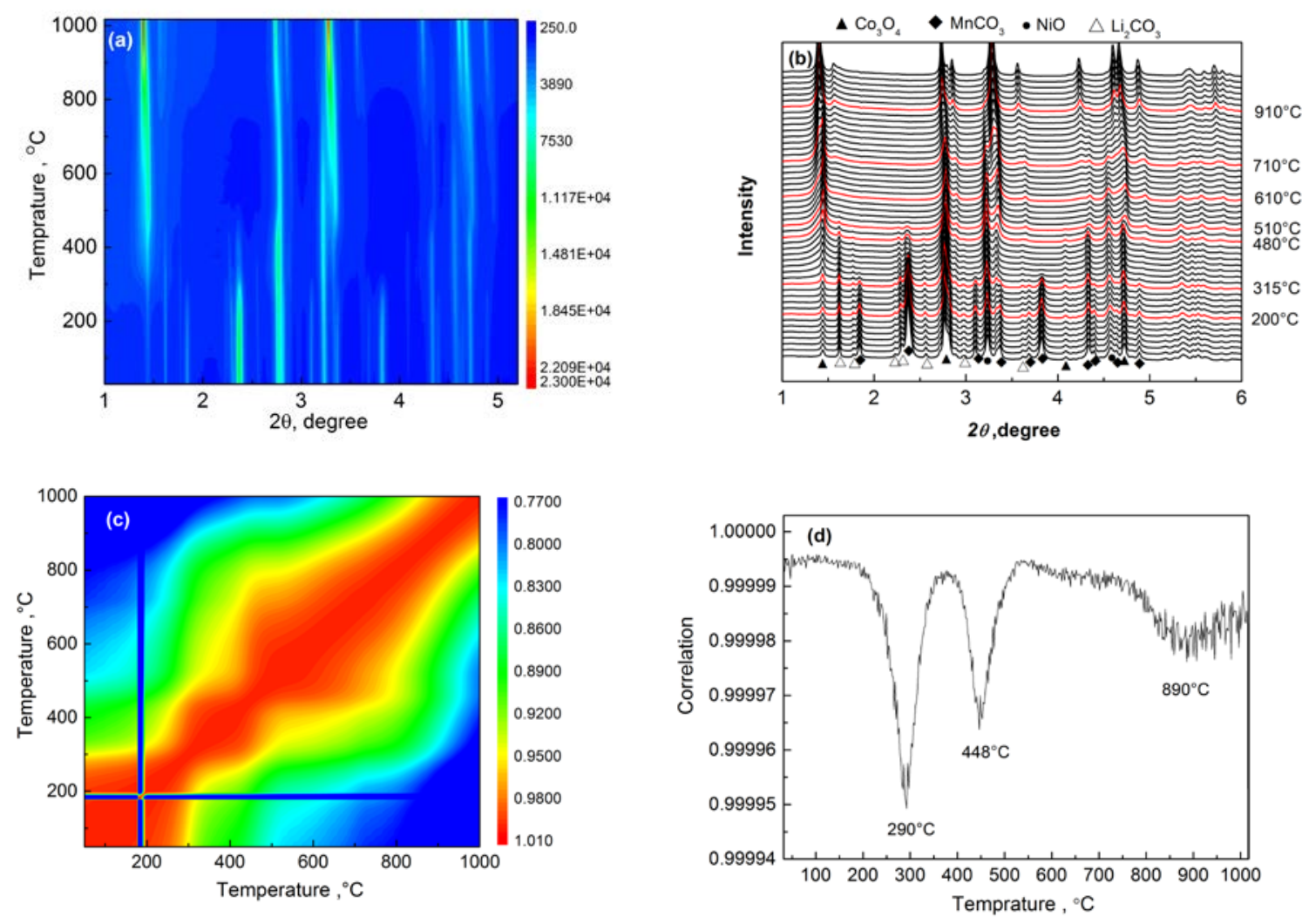

Figure 1. (a) The contour plot of in situ HEXRD patterns and (b) The in-situHEXRD patterns during the thermal treatment of the precursor prepared using the one-step process. (c)Covariance matrix of 2D covariance analysis and (d) 1D covariance analysis of in situ HEXRD profiles. 

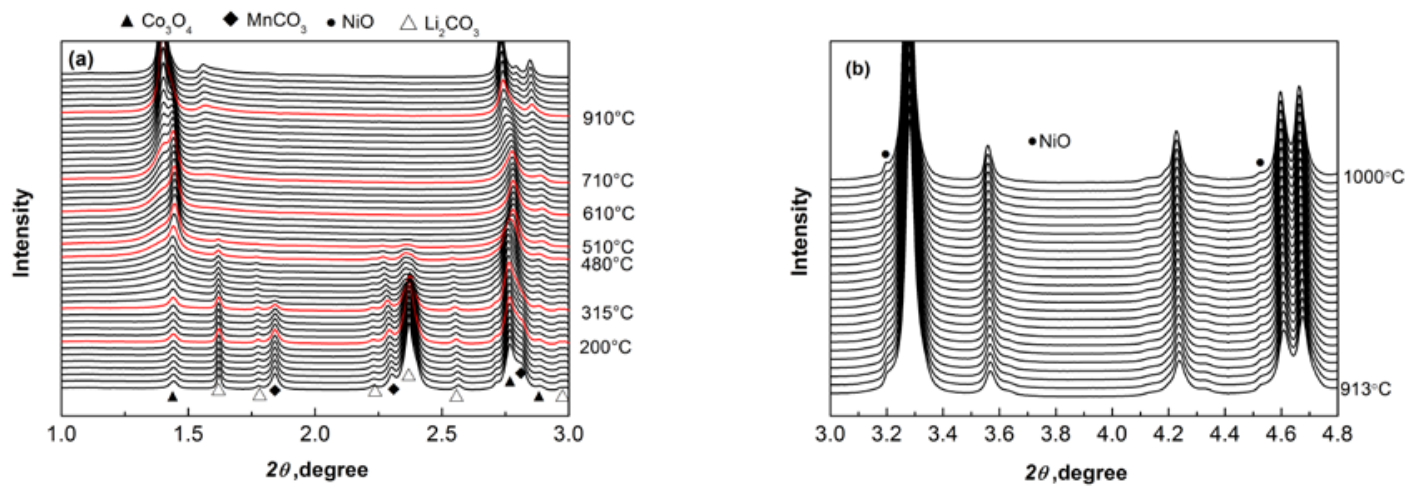

Figure 2. The areal plot of in-situ HEXRD patterns during the thermal treatment of the precursor prepared using the one-step process
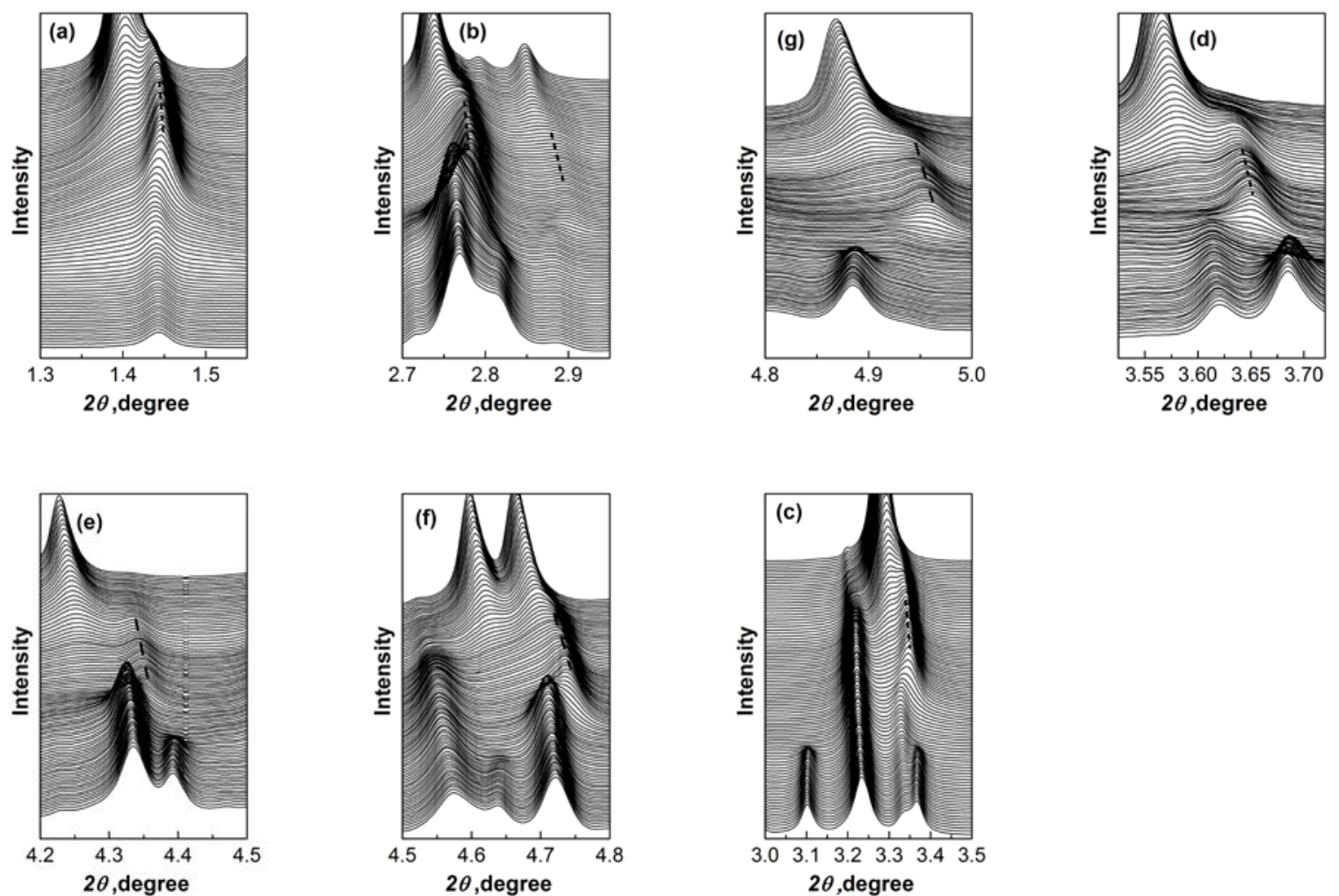

Figure 3. The evolution of an intermediate phase during the thermal treatment of the precursor prepared using the one-step process. 

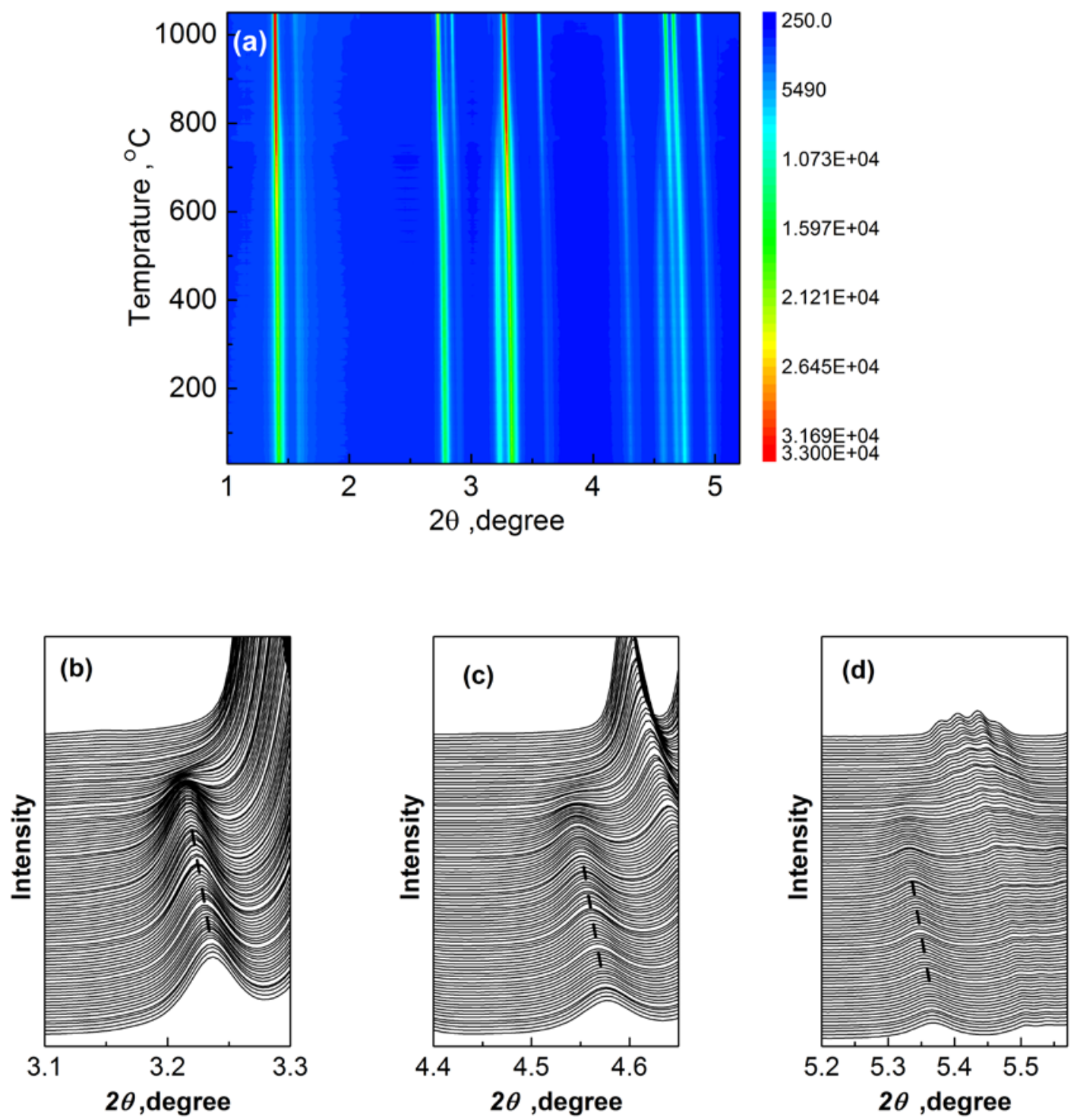

Figure 4. (a)The contour plot of the in-situ HEXRD profiles during the heating of a preheated precursor prepared using the two-step process. (b)- (d) The intensity variation of diffraction peaks from $\mathrm{NiO}$. 

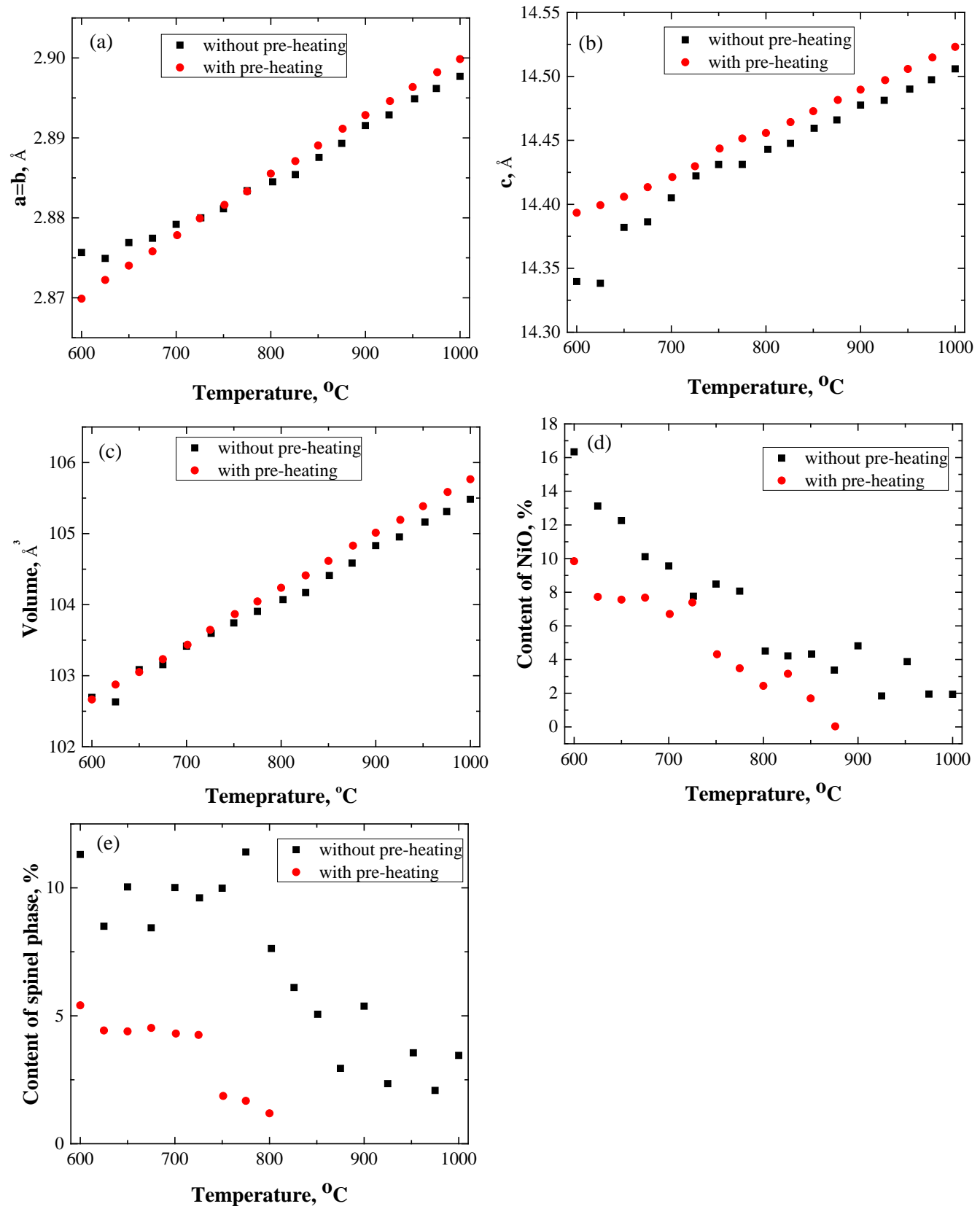

Figure 5 Evolution of cell parameters (a) a and b, (b) c, (c) volume of unit cell, (d) content of $\mathrm{NiO}$ impurity, and (e) content of spinel phase during the solid state synthesis of cathode materials using two different process. 

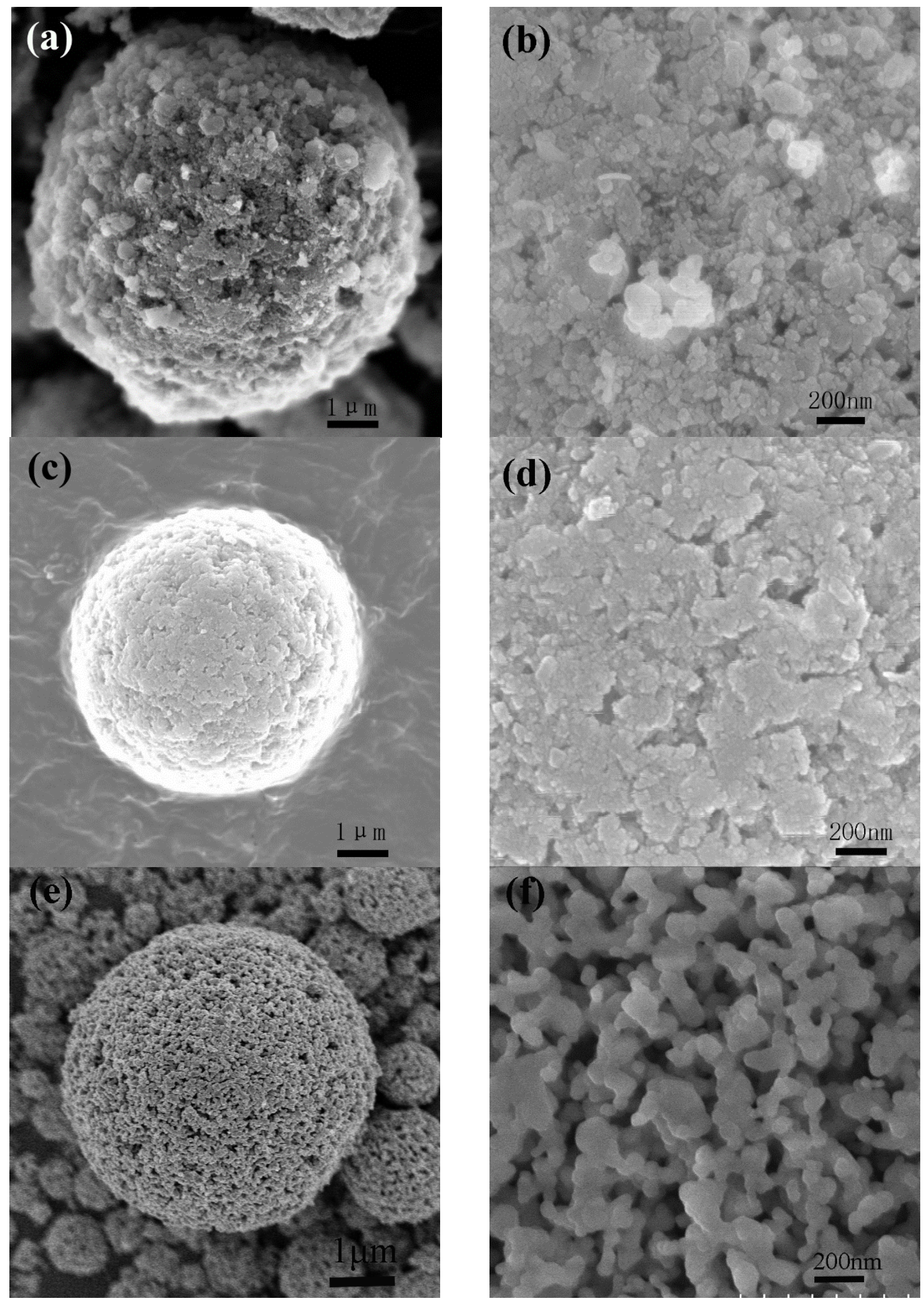

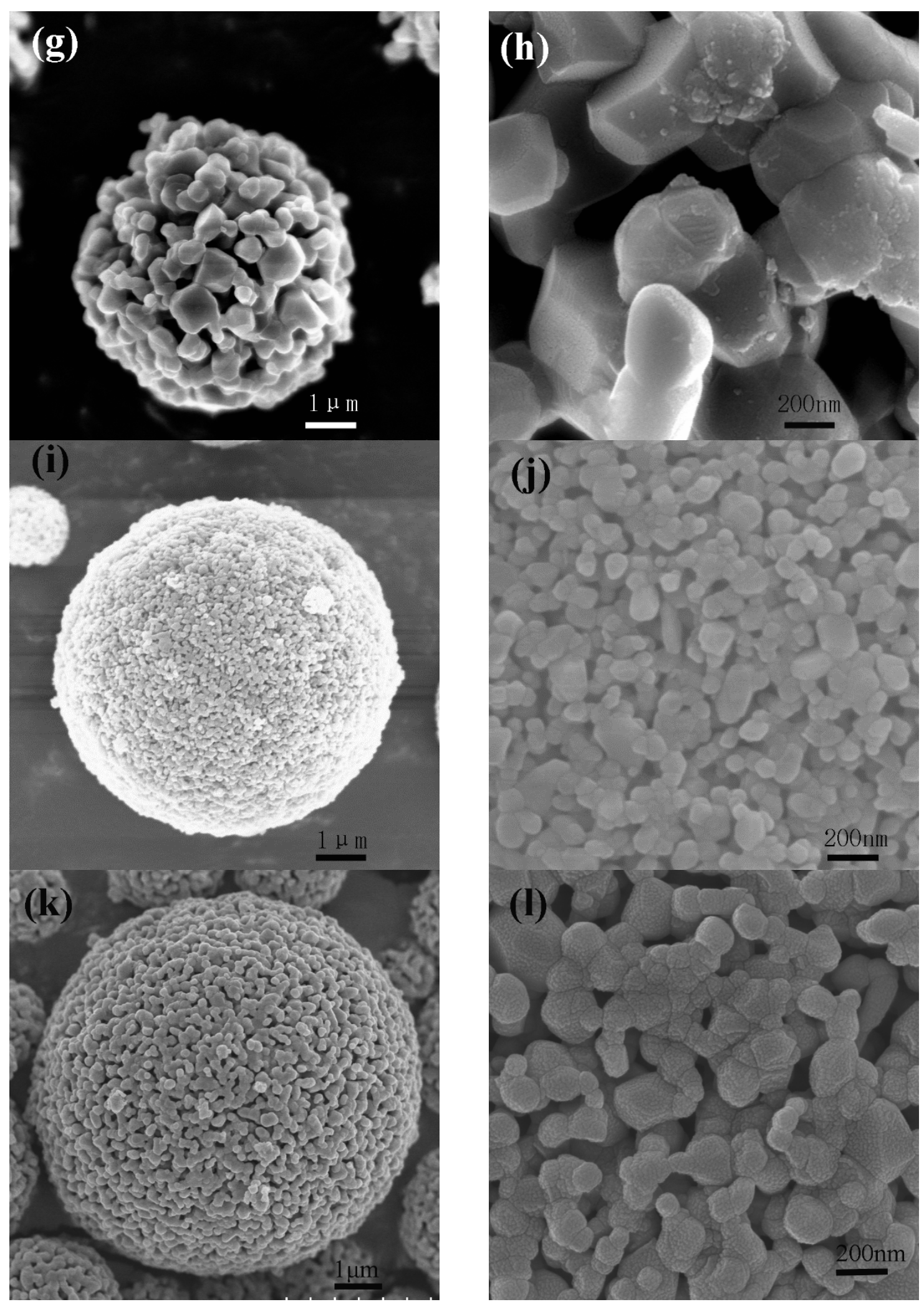

Figure 6. SEM images of the precursors and final powders.(a) and (b) SEM images of the precursors of S1a\&b; (c) and (d) SEM images of the precursors of S2a\&b; (e) and (f) 
SEM images of the final powders of S1a; (g)and (h) SEM images of the final powders of S1b; (i)and (j) SEM images of the final powders of S2a; (k)and (l) SEM images of the final powders of S2b.

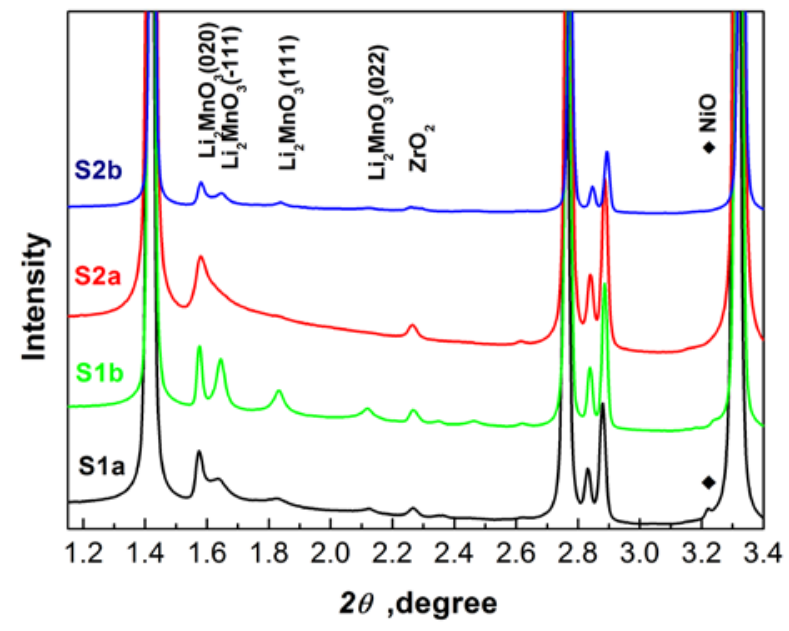

Figure 7. XRD pattern of samplesof 2 Theta between 1.2 to 3.4 degree.
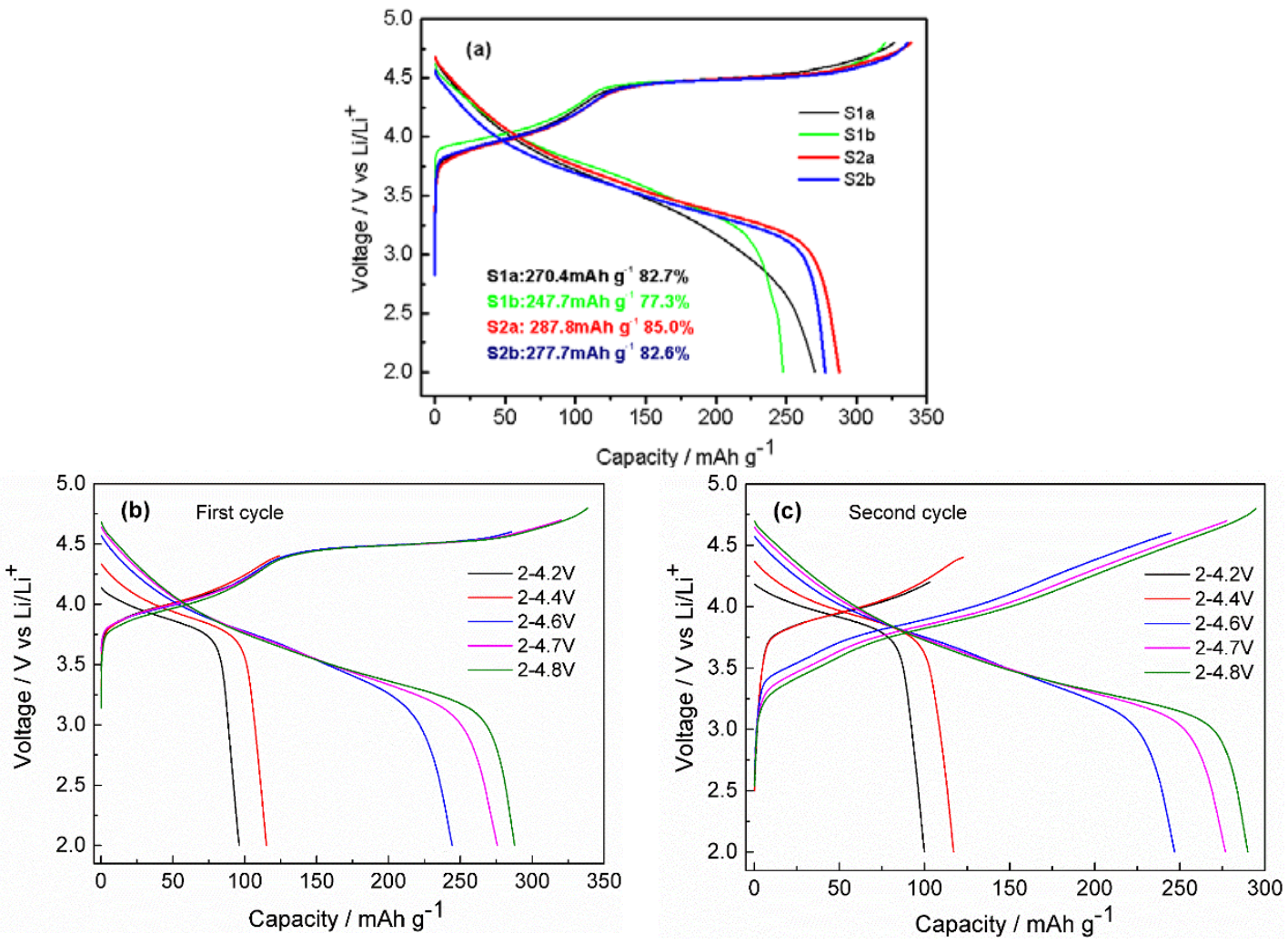

Figure 8. (a) Initial charge and discharge curves of samples; (b) and (c) The voltage profiles of Li/S2a cells that were cycled to different upper cutoff potential (from $4.2 \mathrm{~V}$ to $4.8 \mathrm{~V})$ 

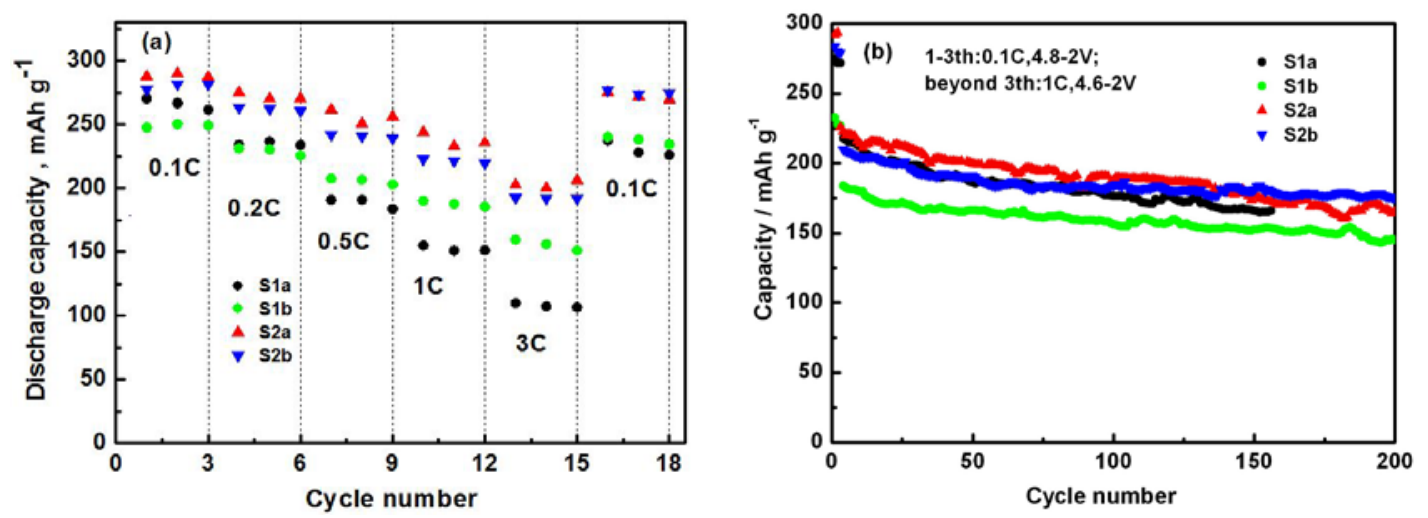

Figure 9. (a) Rate cyclic performance of samples; (b) Cyclic performance of samples ( $0.1 \mathrm{C}$ rate during $1-3$ cycles, $1 \mathrm{C}$ rate after 3 cycles). 


\section{Vitae}

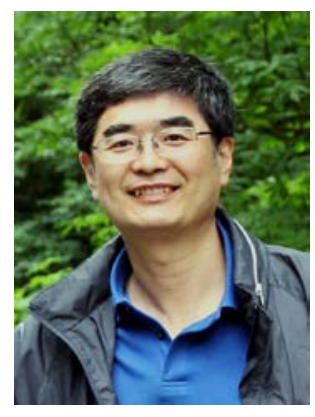

Zhong Wangis currently a professor of engineer at China Automotive Battery Research Institute Co. Ltd. He received his B.S. degree (1990) fromXianJiaotong University,andPh.D. degree (2007)from University of Science and Technology Beijing, China. Hisresearch interests focus on materialsand technology for Li-ion battery and energy storage, with particular focus onthe synthesis in largescale,structure and electrochemicalproperties of cathode materials of advanced Li-ion battery.

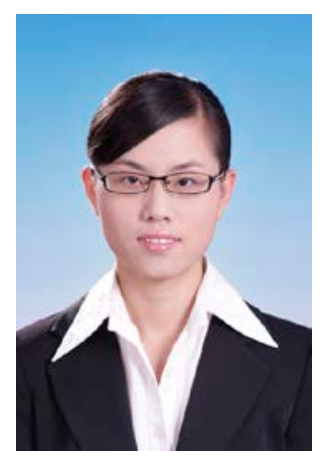

Yanping Yin is currently workingin China Automotive Battery Research Institute Co. Ltd. She received her Master degree (2011) from University of Science and Technology of Beijing. Her researchinterestsin electrode materials for advanced lithium batteries, includingthe process of synthesis and electrochemical behavior of electrode materials.

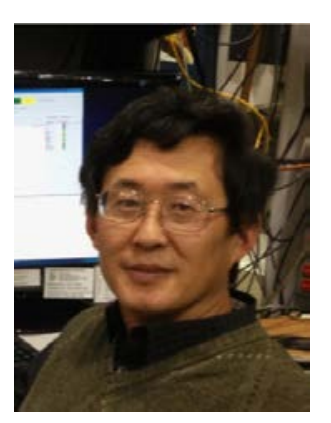

Yang Ren received his M.S. degree in condensed matter physics from the Institute of Physics, Chinese Academy of Science, China, and his Ph.D. degree in Chemical Physics from the University of Groningen, the Netherlands. $\mathrm{He}$ is currently a physicist and lead Beamlinescientist at the Advanced Photon Source, Argonne National Laboratory, USA. Hisresearch interests focus on the structurepropertystudies of materials by utilizing synchrotronX-ray and neutron scattering and other techniques. Hisresearch activities include the investigation of phase transition, correlated electron systems, engineering materials, nanoparticles andnanocomposites, energy storage and conversion materials.

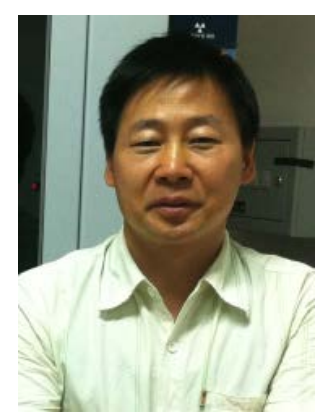

Zhenyao Wang is currently a researcher of General Research Institute of Nonferrous Metals. He received his B.S. degree (1997) from University of Science \& Technology Beijing (USTB), and Ph.D. degree (2008) from Beijing University of Technology. His research interest includes electrode materials for lithium-ion batteries, nanoparticles and nanocomposites. 

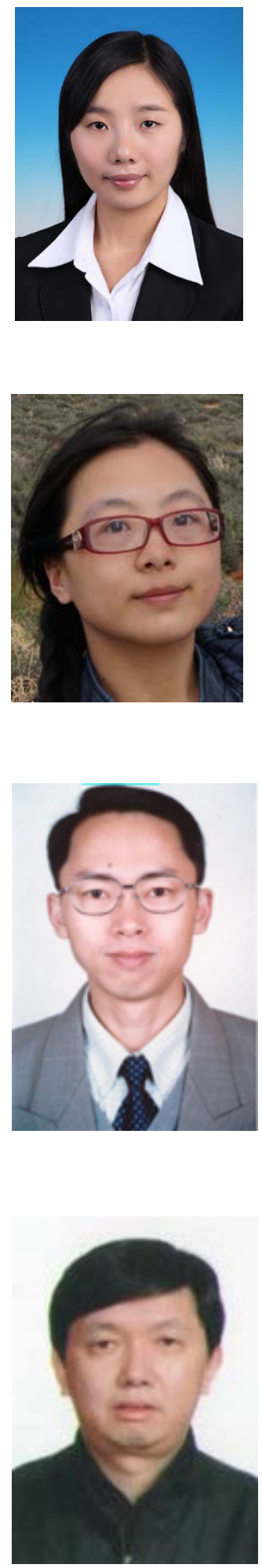

Min Gao received her M.S. degree and Ph.D. degree in Materials Science and Engineeringfrom University of Science and Technology Beijing, China, in 2011 and 2014, respectively. Currently, sheis an engineer at ChinaAutomotive Battery Research Institute Co. Ltd..Her research interests includethe synthesis, structure-property, lithiumion transport and phasetransitions in electrode materials and new type lithium-ionbatteries.

Tianyuan Ma is currently a Ph.D. student in the Materials Science program. Now she is a guest student in Argonne National Laboratory. She obtained her bachelor degree and Master degree in 2008 and 2011 from China University of Geosciences (Beijing) and another Master degree in 2014 from University of Rochester. Her current research is mainly focused on cathode materials for sodium ion battery.

Weidong Zhuang received his M.S. degree and Ph.D. degreein Physical Chemistry of Metallurgyfrom University of Science and Technology Beijing, China, in 1992 and 1995, respectively.Heis currently a professor of engineer atChina Automotive Battery Research Institute Co. Ltd..Hisresearchinterest includes electrode materials for lithium-ion batteries, rare earth luminescent material.

Shigang Lu received hisPh.D. degreein Chemistry fromMoscow State University in 1993.Currently, heis chief scientist at General Research Institute for Nonferrous Metals. Hisresearchinterest includes electrochemistry and its applications. 


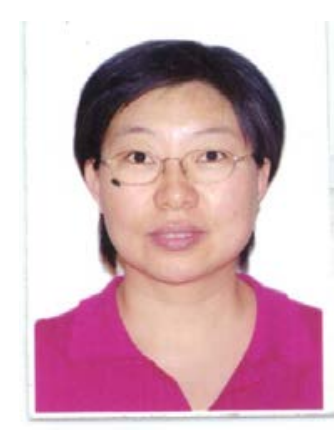

AilingFan received her Ph.D. in 2006 in department of Material physics and chemistry from University of Science and Technology Beijing in China.Now, she works at Beijing University of Technology. Her current research is focused on electrochemical energy conversionmaterials.

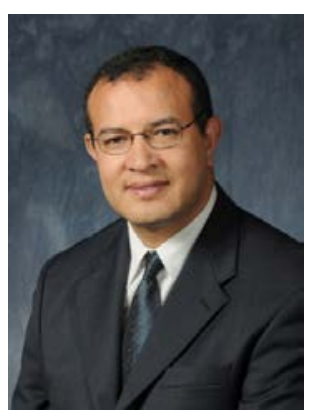

Dr. Khalil Amine is a Distinguished Fellow and the Manager of the Advanced Battery Technology programs at Argonne National Laboratory, where he is responsible for directing the research and development of advanced materials and battery systems for HEV, PHEV, EV, satellite, military and medical applications. Dr. Amine currently serves a member of the U.S. National Research Consul on battery related technologies.

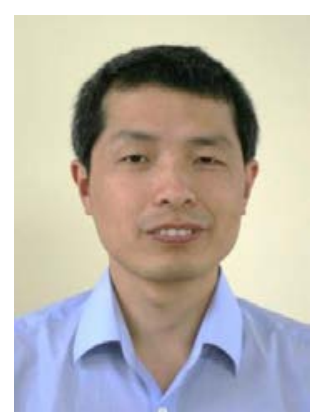

Zonghai Chen is currently a staff scientist of Argonne National Laboratory. He received his B.S. degree (1997) from University of Science and Technology of China, and Ph.D. degree (2004) from Dalhousie University. Hisresearchinterest includes functional electrolytes and electrode materials for advanced lithium batteries, with particular focus on behavior of materials at extreme conditions. 
